\title{
Minimization of material volume of three layer compound cylinder having same materials subjected to internal pressure
}

\author{
A. A. Miraje ${ }^{1^{*}}$, S. A. Patil ${ }^{2}$ \\ ${ }^{1 *}$ Department of Mechanical Engineering, M I T College of Engineering, Pune, INDIA \\ ${ }^{2}$ Department of Mechanical Engineering, Sinhgad Institute of Technology \& Science, Pune, INDIA \\ "Corresponding Author: e-mail: aamiraje.mitcoe@gmail.com, Tel +91-2030273400, Cell.+91-9423871807
}

\begin{abstract}
A thick cylinder storing fluid with large internal pressure has second order non-linear variation in the hoop stress across the wall. Utilization of material of the cylinder is not up to its full capacity. For more uniform hoop stress distribution, compound cylinders are formed by shrinkage process where outer cylinder is heated until it will slide freely over inner cylinder thus exerting the required shrinkage pressure on cooling. Using the calculated shrinkage pressures between two contacting cylinders, it is possible to reduce the hoop stress and make it more or less uniform over the thickness. This paper introduces the methodology for minimization of volume of shrink-fitted three layer compound cylinder and to get equal maximum hoop stresses in all the cylinders. The analytical results are validated in comparison with FEM in ANSYS Workbench. Both the results agree with each other. Thus methodology can be applied to multi-layer compound cylinders used in real-world applications.
\end{abstract}

Keywords: multi-layer cylinders, hoop stress, residual stress, shrink fit, shrinkage (contact) pressure, optimum design.

\section{Introduction}

Compound cylinders have wide applications in hydraulic presses, forging presses, power plants, gas storages, chemical and nuclear plants, military applications etc. To increase the pressure capacity of thick-walled cylinders, two or more cylinders (multi-layer) are shrunk into each other with different diametric differences to form compound cylinder. Manufacturing and assembly process of such compound cylinders of real-world applications introduces some residual stresses. The level of such residual stresses can reach quite significant value and cannot be neglected. These residual stresses can be summed up with hoop stress developed due to internal pressure to find maximum hoop stress in all the cylinders.

The optimization of bi-metal compound cylinders has been proposed and minimized the weight of compound cylinder for a specific pressure by Majzoobi et al. (2006). The variables were shrinkage radius and shrinkage tolerance. They have used SQP technique for optimization, the finite element code, ANSYS for numerical simulation and concluded that high pressure cylinders can partially be replaced by a lower, lighter and cheaper material to reduce the cost and weight of cylinders. Sequential quadratic programming (SQP) is an iterative method for nonlinear optimization. SQP methods solve a sequence of optimization subproblems, each which optimizes a quadratic model of the objective subject to a linearization of the constraints. Two layer compound cylinder has been introduced and optimized intermediate, outer diameter and shrinkage tolerance to get minimum volume of two layer compound cylinders by Patil (2005).

Figure 1 shows that radial $\left(\sigma_{r}\right)$ and hoop $\left(\sigma_{\theta}\right)$ stress distribution across the wall of thick cylinder is non-linear in nature from inner to outer radius of the cylinder. Dimensions and material of the cylinder are usually designed to tolerate the stresses which occur in the inner radius of the cylinder while the stresses reduce sharply towards the outer radius. This necessitates that two or more cylinders are shrunk into each other forming a compound cylinder (multi-layer). However, as a result of shrinking, stress redistribution may occur across the wall of the compound cylinder. 


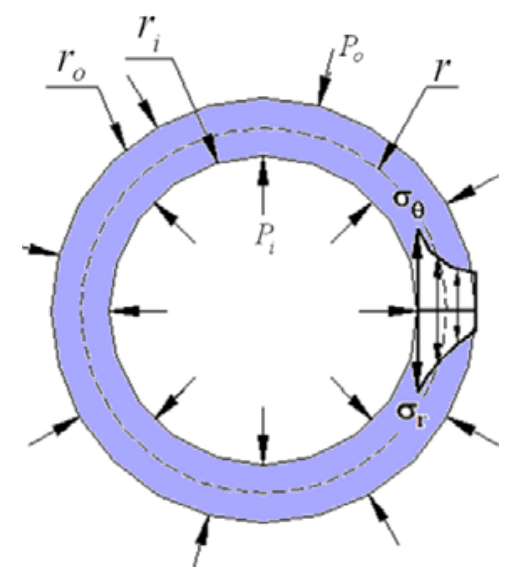

Figure 1. Stress distribution across a single thick-walled cylinder

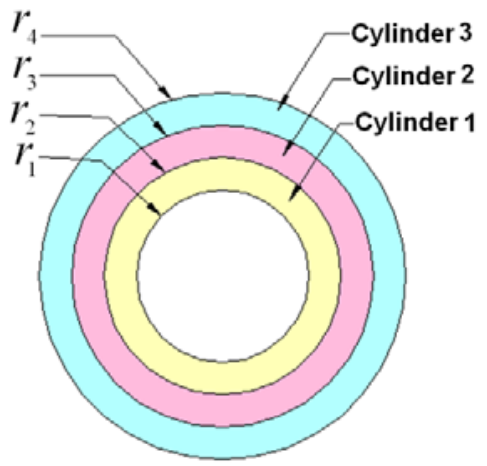

Figure. 2. Three Layer Compound Cylinder

In this paper three cylinders are considered (Figure 2). Cylinder 2 is shrink-fitted on cylinders 1 and cylinder 3 is shrink-fitted on cylinders 2 . The stress redistribution is strongly influenced by shrinking radii (the outer radii of the inner cylinders and the inner radii of the outer cylinders) and shrinking allowances (shrink fit). The main objective of this work is to optimize the values of these parameters so that the minimum material volume for the three layer compound cylinder is achieved and maximum hoop stresses in all three cylinders become equal. This ensures best advantage of the material of the cylinder. Shrink fit is a very efficient way to extend compressive residual stress.

\section{Application of Lame's theory to compound cylinder}

Referring to Figure 1, let

$r_{i} \quad$ Inner radius of cylinder

$r_{o} \quad$ Outer radius of cylinder

$r \quad$ Radius in between inner and outer radius of cylinder

$P_{i} \quad$ Internal pressure in the cylinder

$P_{o} \quad$ External pressure in the cylinder

$\sigma_{\theta} \quad$ Hoop stress in the cylinder

$\sigma_{r} \quad$ Radial stress in the cylinder

$\sigma_{z} \quad$ Axial stress in the cylinder

Radial stress in the cylinder made of homogeneous material is given by

$$
\sigma_{r}=\frac{P_{i} r_{1}^{2}-P_{s 12} r_{2}^{2}}{r_{2}^{2}-r_{1}^{2}}+\frac{r_{1}^{2} r_{2}^{2}\left(P_{s 12}-P_{i}\right)}{r_{2}^{2}-r_{1}^{2}} \frac{1}{r^{2}}
$$

while hoop stress in the cylinder is given by

$$
\sigma_{\theta}=\frac{P_{i} r_{i}^{2}-P_{o} r_{o}^{2}}{r_{o}^{2}-r_{i}^{2}}-\frac{r_{i}^{2} r_{o}^{2}\left(P_{o}-P_{i}\right)}{r_{o}^{2}-r_{i}^{2}} \frac{1}{r^{2}}
$$




\subsection{Radial and hoop stresses in cylinder 1}

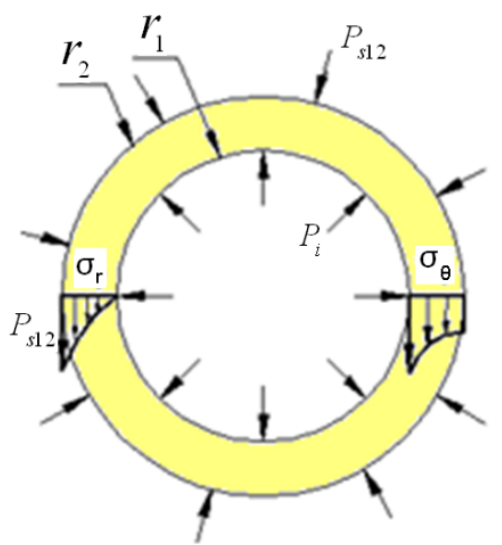

Figure 3. Radial and Hoop Stress distribution in Cylinder 1

Referring to Figures 2 and 3, let
$r_{i}=r_{1}$
Inner radius of cylinder 1
$r_{o}=r_{2}$
Outer radius of cylinder 1
$P_{i}=P_{i}$
Internal pressure acting in the cylinder 1
$P_{o}=P_{s 12}$
Contact pressure between cylinder 1 and 2 acting as external pressure on the cylinder 1

Using equation (A), radial stress in the cylinder 1 is given by

$$
\sigma_{r}=\frac{P_{i} r_{1}^{2}-P_{s 12} r_{2}^{2}}{r_{2}^{2}-r_{1}^{2}}+\frac{r_{1}^{2} r_{2}^{2}\left(P_{s 12}-P_{i}\right)}{r_{2}^{2}-r_{1}^{2}} \frac{1}{r^{2}}
$$

while hoop Stress in the cylinder 1 is given by

$$
\sigma_{\theta}=\frac{P_{i} r_{1}^{2}-P_{s 12} r_{2}^{2}}{r_{2}^{2}-r_{1}^{2}}-\frac{r_{1}^{2} r_{2}^{2}\left(P_{s 12}-P_{i}\right)}{r_{2}^{2}-r_{1}^{2}} \frac{1}{r^{2}}
$$

If $P_{i}=\mathbf{0}$ i. e. there is no internal pressure, radial stress $\sigma_{r}$ and hoop stress $\sigma_{\theta}$ reduce to

$$
\begin{aligned}
& \sigma_{r}=-P_{s 12} \frac{r_{2}^{2}}{r_{2}^{2}-r_{1}^{2}}\left(1-\frac{r_{1}^{2}}{r^{2}}\right) \\
& \sigma_{\theta}=-P_{s 12} \frac{r_{2}^{2}}{r_{2}^{2}-r_{1}^{2}}\left(1+\frac{r_{1}^{2}}{r^{2}}\right)
\end{aligned}
$$

$\sigma_{r}$ is maximum at outer radius $r_{o}=r_{2}$. Using equation (2 a)

$$
\sigma_{r \max \left(a t r_{2}\right)}=-P_{s 12}
$$

$\sigma_{r}$ is zero at inner radius $r_{i}=r_{1}$.

Using equation (2 b), $\sigma_{\theta}$ at outer radius $r_{o}=r_{2}$ is written as follows

$$
\sigma_{\theta\left(a t r_{2}\right)}=-P_{s 12}\left[\frac{r_{2}^{2}+r_{1}^{2}}{r_{2}^{2}-r_{1}^{2}}\right]
$$

$\sigma_{\theta}$ is maximum at inner radius $r_{i}=r_{1}$ which can be written by using equation (2 b)

$$
\sigma_{\theta \max \left(a t r_{1}\right)}=-\left[\frac{2 P_{s 12} r_{2}^{2}}{r_{2}^{2}-r_{1}^{2}}\right]
$$




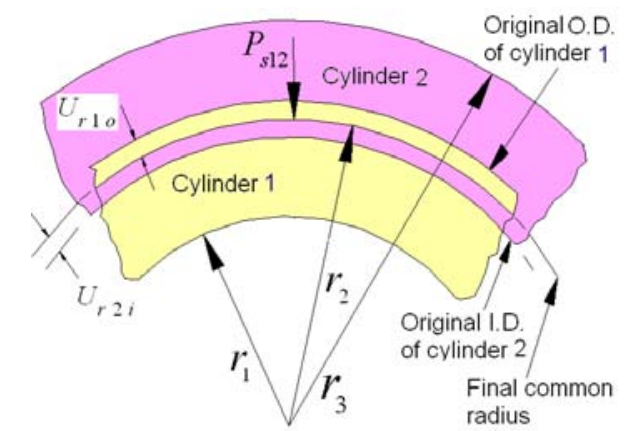

Figure 4. Shrinkage allowance between cylinders 1 and 2

Referring to Figure 4, let

$\begin{array}{cl}\varepsilon_{\theta 10} & \text { Hoop strain in the outer wall of cylinder } 1 \\ U_{r 10} & \text { Radial displacement at outer wall of cylinder } 1 \\ v & \text { Poisson's ratio }\end{array}$

In the presented study open type compound cylinder is considered, wherein axial stress $\sigma_{z}$ produced due to internal pressure is zero. Values of hoop strain by using plane stress hypothesis and plane strain hypothesis at the same interference comes out to be very close to each other. Hence plane stress hypothesis can be assumed.

The radial displacement $U_{r 1 o}$ at outer wall (at $r_{o}=r_{2}$ ) of cylinder 1 is given by using equations (3) and (4)

$$
\begin{aligned}
& \varepsilon_{\theta 10}=\frac{U_{r 10}}{r_{2}}=\frac{1}{E}\left[\sigma_{\theta}-v \sigma_{r}\right]=\frac{1}{E}\left[-P_{s 12}\left(\frac{r_{2}^{2}+r_{1}^{2}}{r_{2}^{2}-r_{1}^{2}}\right)-v\left(-P_{s 12}\right)\right] \\
& U_{r 10}=\frac{-P_{s 12} r_{2}}{E}\left[\left(\frac{r_{2}^{2}+r_{1}^{2}}{r_{2}^{2}-r_{1}^{2}}\right)-v\right]
\end{aligned}
$$

\subsection{Radial and hoop stresses in cylinder 2}

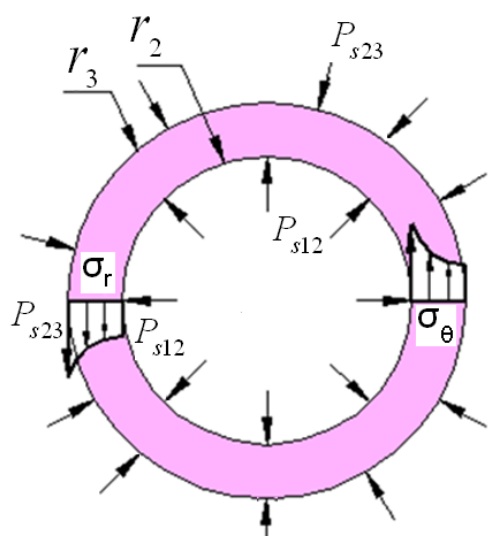

Figure 5. Radial and hoop stress distribution in Cylinder 2 due to contact pressure $P_{s 12}$ (acting as internal pressure) and contact pressure $P_{s 23}$ (acting as external pressure)

Referring to Figure 5, let
$r_{i}=r_{2}$
Inner radius of cylinder 2
$r_{o}=r_{3}$
Outer radius of cylinder 2
$P_{i}=P_{s 12}$
Contact pressure between cylinder 1 and 2 acting as internal pressure on the cylinder 2
$P_{o}=P_{s 23}$
Contact pressure between cylinder 2 and 3 acting as external pressure on the cylinder 2

Using equation (A), radial stress in the cylinder 2 is given by

$$
\sigma_{r}=\frac{P_{s 12} r_{2}^{2}-P_{s 23} r_{3}^{2}}{r_{3}^{2}-r_{2}^{2}}+\frac{r_{2}^{2} r_{3}^{2}\left(P_{s 23}-P_{s 12}\right)}{r_{3}^{2}-r_{2}^{2}} \frac{1}{r^{2}}
$$


Radial stress in the cylinder 2 at inner radius $r_{i}=r_{2}$ is given by

$$
\sigma_{r\left(a t r_{2}\right)}=-P_{s 12}
$$

Radial stress in the cylinder 2 at outer radius $r_{o}=r_{3}$ is given by

$$
\sigma_{r\left(a t r_{3}\right)}=-P_{s 23}
$$

Using equation (B), hoop stress in the cylinder 2 is given by

$$
\sigma_{\theta}=\frac{P_{s 12} r_{2}^{2}-P_{s 22} r_{3}^{2}}{r_{3}^{2}-r_{2}^{2}}-\frac{r_{2}^{2} r_{3}^{2}\left(P_{s 23}-P_{s 12}\right)}{r_{3}^{2}-r_{2}^{2}} \frac{1}{r^{2}}
$$

Hoop stress in the cylinder 2 at inner radius $r_{i}=r_{2}$ is given by

$$
\sigma_{\theta \max \left(a t r_{2}\right)}=\frac{P_{s 12}\left(r_{3}^{2}+r_{2}^{2}\right)}{r_{3}^{2}-r_{2}^{2}}-\frac{2 P_{s 23}\left(r_{3}^{2}\right)}{r_{3}^{2}-r_{2}^{2}}
$$

Hoop stress in the cylinder 2 is maximum at inner radius $r_{2}$ (See Figure 5). Hoop stress in the cylinder 2 at outer radius $r_{o}=r_{3}$ is given by

$$
\sigma_{\theta\left(a t r_{3}\right)}=\frac{2 P_{s 12}\left(r_{2}^{2}\right)}{r_{3}^{2}-r_{2}^{2}}-\frac{P_{s 23}\left(r_{3}^{2}+r_{2}^{2}\right)}{r_{3}^{2}-r_{2}^{2}}
$$

Referring to Figure 4, let

$$
\begin{array}{ll}
\varepsilon_{\theta 2 i} & \text { Hoop strain in the inner wall of cylinder } 2 \\
U_{r 2 i} & \text { Radial displacement at inner wall of cylinder } 2
\end{array}
$$

Radial displacement $U_{r 2 i}$ at inner wall (at $r=r_{2}$ ) of cylinder 2 is given by using equations (7) and (9).

$$
\begin{aligned}
& \varepsilon_{\theta 2 i}=\frac{U_{r 2 i}}{r_{2}}=\frac{1}{E}\left[\sigma_{\theta}-v \sigma_{r}\right]=\frac{1}{E}\left[\frac{P_{s 12}\left(r_{3}^{2}+r_{2}^{2}\right)}{r_{3}^{2}-r_{2}^{2}}-\frac{2 P_{s 23}\left(r_{3}^{2}\right)}{r_{3}^{2}-r_{2}^{2}}-v\left(-P_{s 12}\right)\right] \\
& U_{r 2 i}=\frac{r_{2}}{E}\left[P_{s 12}\left(\frac{r_{3}^{2}+r_{2}^{2}}{r_{3}^{2}-r_{2}^{2}}+v\right)-\frac{2 P_{s 23}\left(r_{3}^{2}\right)}{r_{3}^{2}-r_{2}^{2}}\right]
\end{aligned}
$$

Total interference $\delta_{12}$ at the contact between cylinder 1 and 2 is given by algebraic sum of radial displacement $U_{r 2 i}$ at inner wall of cylinder 2 and radial displacement $U_{\text {r1o }}$ at outer wall of cylinder 1.

Using equations (6), (11) and referring to Figure 4, we can write $\delta_{12}$ as follows

$$
\delta_{12}=U_{r 2 i}-U_{r 10}=\frac{P_{s 12} r_{2}}{E}\left[\left(\frac{r_{3}^{2}+r_{2}^{2}}{r_{3}^{2}-r_{2}^{2}}\right)+\left(\frac{r_{2}^{2}+r_{1}^{2}}{r_{2}^{2}-r_{1}^{2}}\right)\right]-\frac{2 P_{s 23} r_{2}}{E}\left[\frac{\left(r_{3}^{2}\right)}{r_{3}^{2}-r_{2}^{2}}\right]
$$

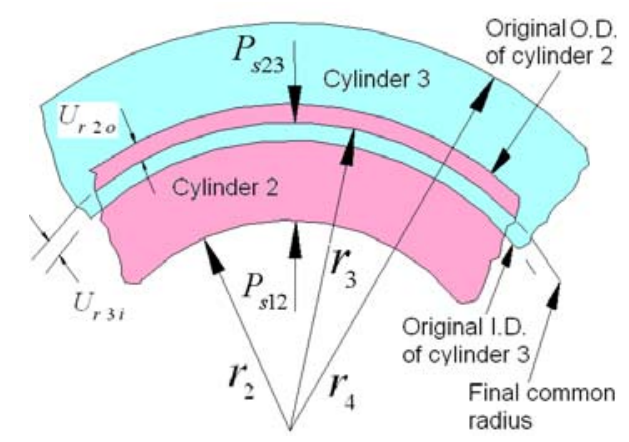

Figure 6. Shrinkage allowance between cylinders 2 and 3

Referring to Figure 6, let
$\varepsilon_{\theta 2 o}$
Hoop strain in the outer wall of cylinder 2
$U_{\text {r2o }}$
Radial displacement at outer wall of cylinder 2 
Radial displacement $U_{r 2 o}$ at outer wall (at $r=r_{3}$ ) of cylinder 2 is given by using equations (8) and (10).

$$
\begin{aligned}
& \varepsilon_{\theta 2 o}=\frac{U_{r 2 o}}{r_{3}}=\frac{1}{E}\left[\sigma_{\theta}-v \sigma_{r}\right]=\frac{1}{E}\left[\frac{2 P_{s 12}\left(r_{2}^{2}\right)}{r_{3}^{2}-r_{2}^{2}}-\frac{P_{s 23}\left(r_{3}^{2}+r_{2}^{2}\right)}{r_{3}^{2}-r_{2}^{2}}-v\left(-P_{s 23}\right)\right] \\
& U_{r 2 o}=\frac{r_{3}}{E}\left[\frac{2 P_{s 12} r_{2}^{2}}{r_{3}^{2}-r_{2}^{2}}-P_{s 23}\left(\frac{r_{3}^{2}+r_{2}^{2}}{r_{3}^{2}-r_{2}^{2}}-v\right)\right]
\end{aligned}
$$

\subsection{Radial and hoop stresses in cylinder 3}

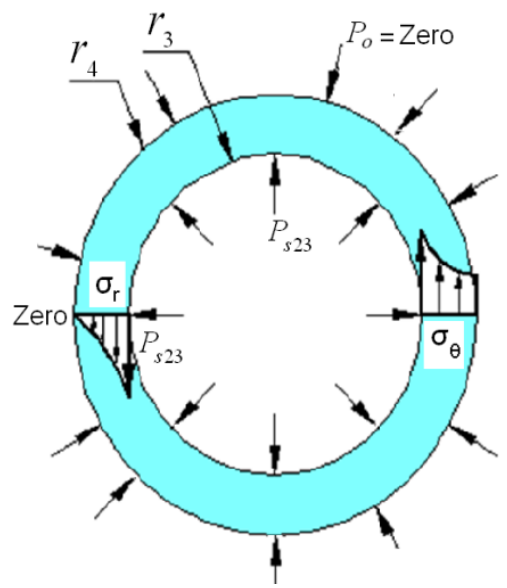

Figure 7. Radial and Hoop Stress distribution in Cylinder 3 due to contact pressure $P_{s 23}$ only ( acting as internal pressure )

Referring to Figure 7, let
$r_{i}=r_{3}$
Inner radius of cylinder 3
$r_{o}=r_{4}$
Outer radius of cylinder 3
$P_{i}=P_{s 23}$
Contact pressure between cylinder 2 and 3 acting as internal pressure on the cylinder 3
$P_{o}=$ Zero
External pressure on the cylinder 3

Using equation (A), radial stress in the cylinder 3 at inner radius $r_{i}=r_{3}$ is given by

$$
\sigma_{r\left(a t r_{3}\right)}=-P_{s 23}
$$

and radial stress in the cylinder 3 at outer radius $r_{o}=r_{4}$ is given by

$$
\sigma_{r\left(a t r_{4}\right)}=0
$$

Using equation (B), hoop stress in the cylinder 3 at inner radius $r_{i}=r_{3}$ is given by

$$
\sigma_{\theta \max \left(a t r_{3}\right)}=\frac{P_{s 23}\left(r_{4}^{2}+r_{3}^{2}\right)}{r_{4}^{2}-r_{3}^{2}}
$$

Hoop stress in the cylinder 3 at outer radius $r_{o}=r_{4}$ is given by

$$
\sigma_{\theta\left(a t r_{4}\right)}=\frac{2 P_{s 23}\left(r_{3}^{2}\right)}{r_{4}^{2}-r_{3}^{2}}
$$

$\sigma_{\theta}$ is maximum at inner radius $r_{2}$ as compared to at outer radius $r_{4}$.

Contact pressure $P_{s 23}$ is acting as internal pressure on the cylinder 3 and external pressure on the cylinder 3 is assumed as zero. Residual hoop stress $\sigma_{\theta}$ due to $P_{\text {s23 }}$ on the cylinder 3 at $r_{i}=r_{3}$ and $r_{o}=r_{4}$ is given by equations (16) and (17).

Referring to Figures 6 and 7, let

$\varepsilon_{\theta 3 i} \quad$ Hoop strain in the inner wall of cylinder 3

$U_{r 3 i} \quad$ Radial displacement at inner wall of cylinder 3 
Radial displacement $U_{r 3 i}$ at inner wall (at $r_{i}=r_{3}$ ) of cylinder 3 is given by using equations (14) and (16).

$$
\begin{aligned}
& \varepsilon_{\theta 3 i}=\frac{U_{r 3 i}}{r_{3}}=\frac{1}{E}\left[\sigma_{\theta}-v \sigma_{r}\right]=\frac{1}{E}\left[\frac{P_{s 23}\left(r_{4}^{2}+r_{3}^{2}\right)}{r_{4}^{2}-r_{3}^{2}}-v\left(-P_{s 23}\right)\right] \\
& U_{r 3 i}=\frac{P_{s 23} r_{3}}{E}\left[\frac{\left(r_{4}^{2}+r_{3}^{2}\right)}{\left(r_{4}^{2}-r_{3}^{2}\right)}+v\right]
\end{aligned}
$$

Total interference $\delta_{23}$ at the contact between cylinder 2 and 3 is given by algebraic sum of radial displacement $U_{r 3 i}$ at inner wall of cylinder 3 and radial displacement $U_{r 20}$ at outer wall of cylinder 2. Using equations (13) and (18),

$$
\delta_{23}=U_{r 3 i}-U_{r 20}=\frac{P_{s 23} r_{3}}{E}\left[\left(\frac{r_{4}^{2}+r_{3}^{2}}{r_{4}^{2}-r_{3}^{2}}\right)+\left(\frac{r_{3}^{2}+r_{2}^{2}}{r_{3}^{2}-r_{2}^{2}}\right)\right]-\frac{2 P_{s 12} r_{3}}{E}\left[\frac{r_{2}^{2}}{r_{3}^{2}-r_{2}^{2}}\right]
$$

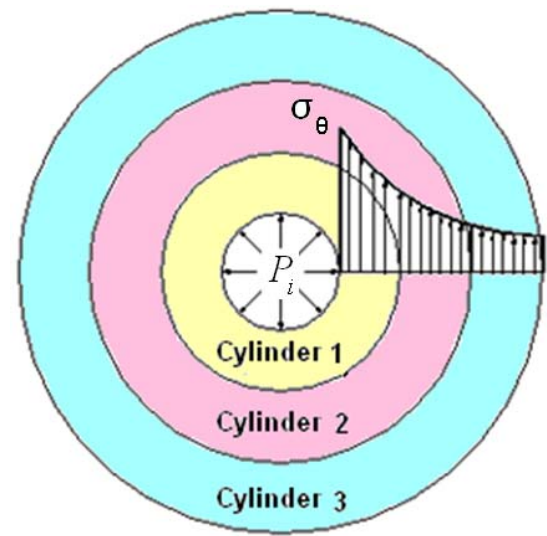

Figure 8. Tensile hoop stress $\sigma_{\theta}$ in all three cylinders due to internal pressure $P_{i}$ only

Referring to Figure 8, if the cylinder is subjected to internal pressure $P_{i}$ (and no external pressure $P_{o}=0$ ), tensile hoop stress is caused in all three cylinders which is given by equation (B), where $P_{i}=P_{i}$ at $r_{i}=r_{1}$ and $P_{o}=0$ at $r_{o}=r_{4}$.

$$
\sigma_{\theta}=\frac{P_{i} r_{1}^{2}}{r_{4}^{2}-r_{1}^{2}}\left[\frac{r_{4}^{2}}{r^{2}}+1\right]
$$

Tensile hoop stress due to internal pressure $P_{i}$ and residual hoop stress due to shrink fit have been superimposed to get the resultant hoop stresses. The resultant maximum hoop stress occurred at the inner surfaces of all three cylinders.

Maximum hoop stress at the inner surfaces of cylinder 1 (at $r_{1}$ ) is given by adding equations (20) and (5). (Refer to Figure 9).

$$
\sigma_{\theta 1}=P_{i}\left[\frac{r_{4}^{2}+r_{1}^{2}}{r_{4}^{2}-r_{1}^{2}}\right]-2 P_{s 12}\left[\frac{r_{2}^{2}}{r_{2}^{2}-r_{1}^{2}}\right]
$$

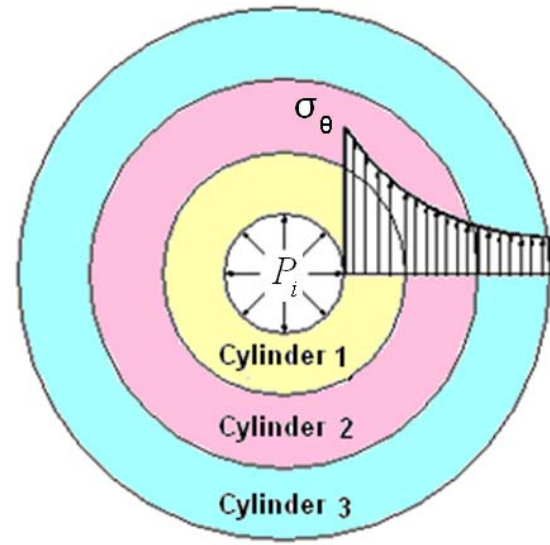

(a) Tensile hoop stress due to internal pressure $P_{i}$

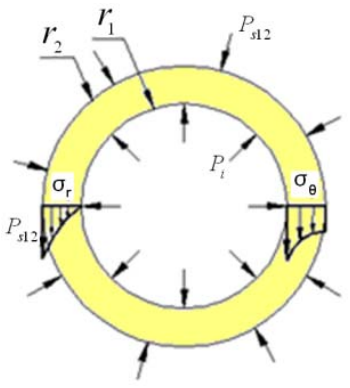

(b) Residual hoop stress due to contact pressure $P_{s 12}$

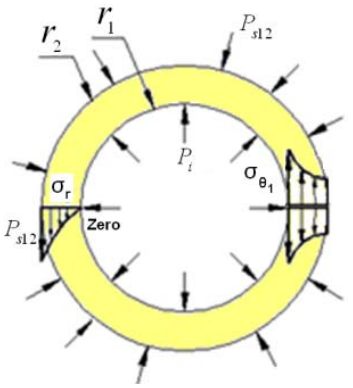

(c) Resultant hoop stress $\left(\sigma_{\theta 1}\right)$

Figure 9. Superposition of tensile hoop stress due to internal pressure $P_{i} \&$ residual hoop stress due to contact pressure $P_{s 12}$ in cylinder 1 
Maximum hoop stress at the inner surfaces of cylinder 2 (at $r_{2}$ ) is given by adding $\sigma_{\theta}$ given by equations (20) and (9). (Refer to Figure 10).

$$
\sigma_{\theta 2}=\frac{P_{i} r_{1}^{2}}{r_{2}^{2}}\left[\frac{r_{4}^{2}+r_{2}^{2}}{r_{4}^{2}-r_{1}^{2}}\right]+\frac{P_{s 12}\left(r_{3}^{2}+r_{2}^{2}\right)-2 P_{s 23} r_{3}^{2}}{r_{3}^{2}-r_{2}^{2}}
$$

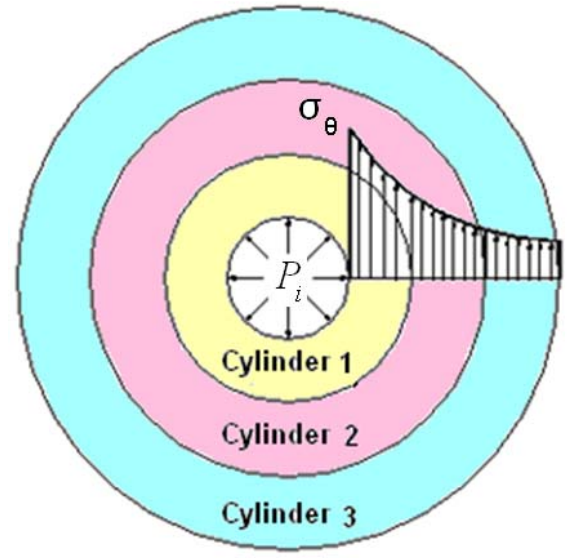

a) Tensile hoop stress due to internal pressure $P_{i}$

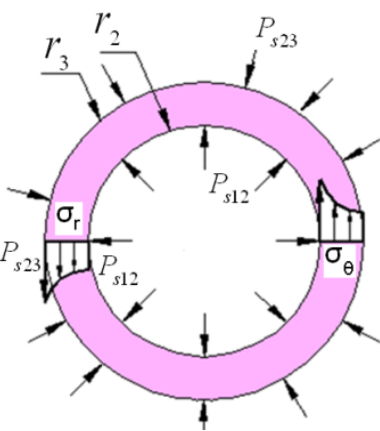

(b) Residual hoop stress due to contact pressure $P_{s 12}$ and $P_{s 23}$

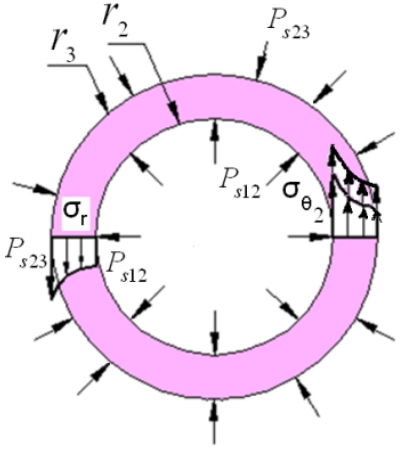

(c) Resultant hoop stress $\left(\sigma_{\theta 2}\right)$

Figure 10. Superposition of tensile hoop stress due to internal pressure $P_{i} \&$ residual hoop stress due to contact pressure $P_{s 12}$ and $P_{s 23}$ in cylinder 2

Maximum hoop stress at the inner surfaces of cylinder 3 (at $r_{3}$ ) is given by adding $\sigma_{\theta}$ given by equations (20) and (16). (Refer to Figure 11).

$$
\sigma_{\theta 3}=\frac{P_{i} r_{1}^{2}}{r_{3}^{2}}\left[\frac{r_{4}^{2}+r_{3}^{2}}{r_{4}^{2}-r_{1}^{2}}\right]+P_{s 23}\left[\frac{r_{4}^{2}+r_{3}^{2}}{r_{4}^{2}-r_{3}^{2}}\right]
$$

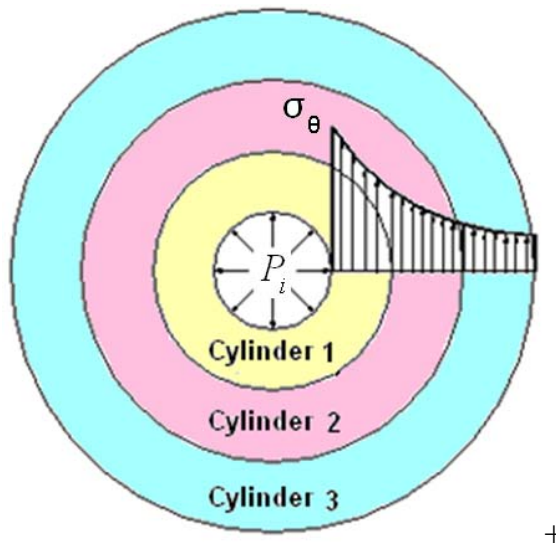

(a) Tensile hoop stress due to internal pressure $P_{i}$

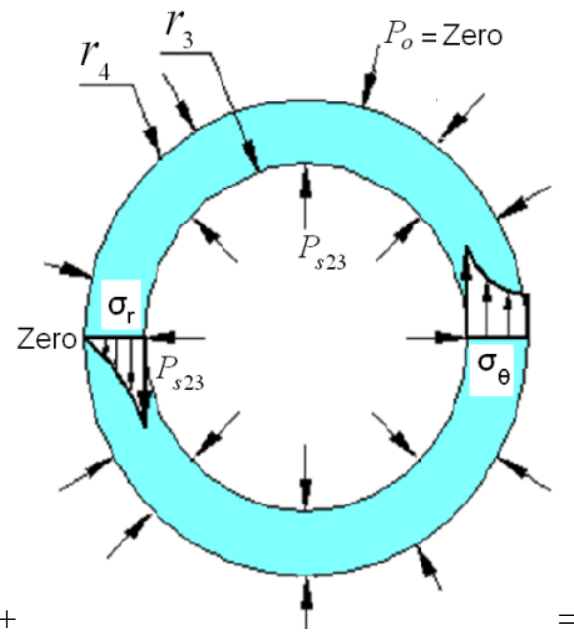

(b) Residual hoop stress due to contact pressure $P_{s 23}$

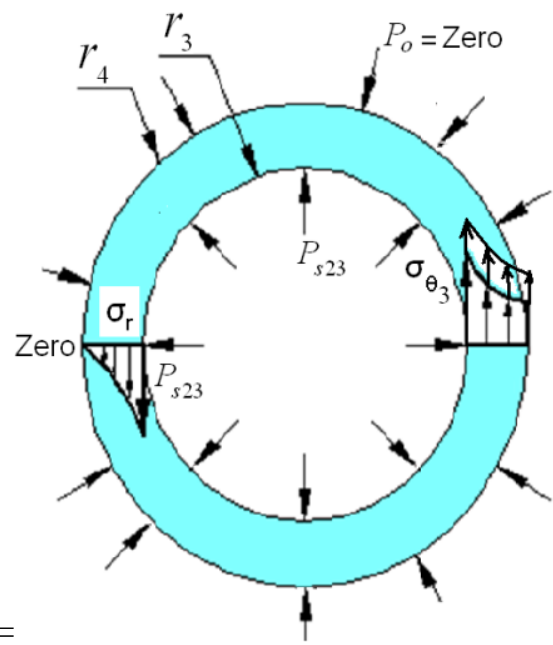

(c) Resultant hoop stress $\left(\sigma_{\theta 3}\right)$

Figure 11. Superposition of tensile hoop stress due to internal pressure $P_{i}$ and residual hoop stress due to contact pressure $P_{s 23}$ in cylinder 3 


\section{Optimum Design Methodology for Three Layer Compound Cylinder}

After finding hoop stresses at all the radii, the principle of superposition is applied, i.e. the various stresses are then combined algebraically to produce the resultant hoop stresses in the compound cylinder subjected to both shrinkage pressures and internal pressure $P_{i}$.

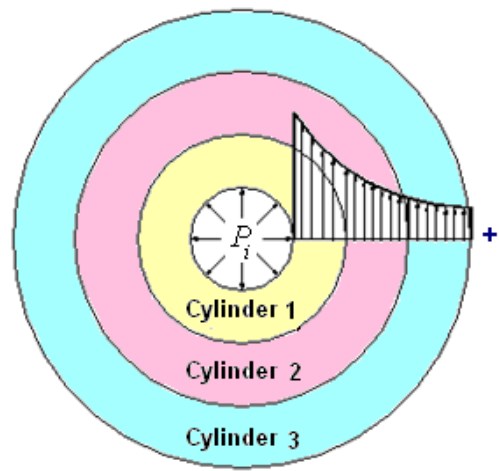

a) Hoop stress due to $P_{i}$

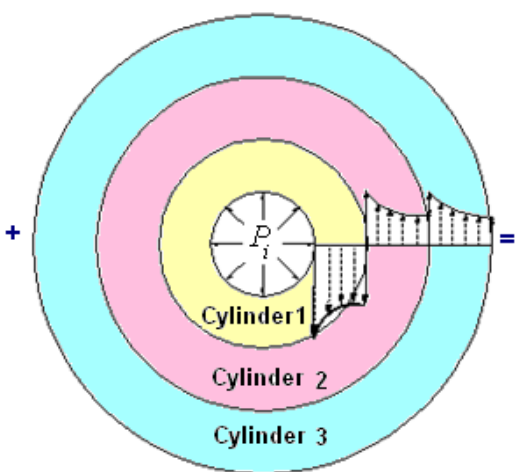

b) Residual hoop stress due to $P_{s 12} \& P_{s 23}$

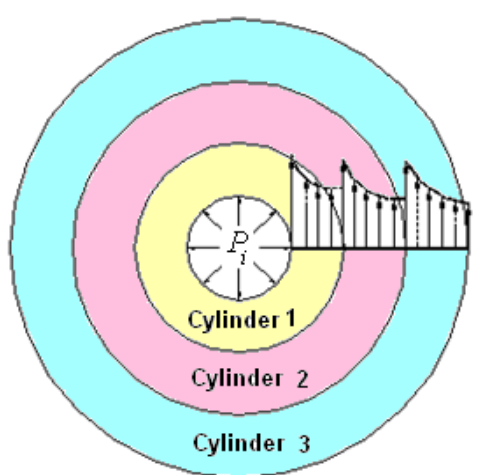

(c) Resultant hoop stress

Figure 12: Superposition of hoop stress due to $P_{i} \&$ residual hoop stresses due to $P_{s 12} \& P_{s 23}$ in all cylinders

To obtain optimum values of the contact pressures $P_{s 12}$ and $P_{s 23}$ which will produce equal hoop stresses in all the three cylinders, maximum hoop stresses given by the equations (21), (22) and (23) must be equated.

By equating equations (21) and (22) i. e. $\sigma_{\theta 1}=\sigma_{\theta 2}$ and rearranging,

$$
P_{s 12}\left[\frac{2 r_{2}^{2}}{r_{2}^{2}-r_{1}^{2}}+\frac{r_{3}^{2}+r_{2}^{2}}{r_{3}^{2}-r_{2}^{2}}\right]=P_{i}\left[\frac{r_{4}^{2}+r_{1}^{2}}{r_{4}^{2}-r_{1}^{2}}-\frac{r_{1}^{2}}{r_{2}^{2}}\left[\frac{r_{4}^{2}+r_{2}^{2}}{r_{4}^{2}-r_{1}^{2}}\right]\right]+P_{s 23} \frac{2 r_{3}^{2}}{r_{3}^{2}-r_{2}^{2}}
$$

Let $C_{1}=\frac{r_{2}}{r_{1}}=\frac{d_{2}}{d_{1}}, C_{2}=\frac{r_{3}}{r_{2}}=\frac{d_{3}}{d_{2}}, C_{3}=\frac{r_{4}}{r_{3}}=\frac{d_{4}}{d_{3}}$

where $d_{1}, d_{2}, d_{3}, d_{4}$ are diameters corresponding to radii $r_{1}, r_{2}, r_{3}, r_{4}$.

Hence $C_{1} C_{2}=\frac{r_{2}}{r_{1}} \cdot \frac{r_{3}}{r_{2}}=\frac{r_{3}}{r_{1}}, C_{2} C_{3}=\frac{r_{3}}{r_{2}} \frac{r_{4}}{r_{3}}=\frac{r_{4}}{r_{2}}, C_{1} C_{2} C_{3}=\frac{r_{2}}{r_{1}} \cdot \frac{r_{3}}{r_{2}} \frac{r_{4}}{r_{3}}=\frac{r_{4}}{r_{1}}$

Let $j=\frac{2 r_{2}^{2}}{r_{2}^{2}-r_{1}^{2}}+\frac{r_{3}^{2}+r_{2}^{2}}{r_{3}^{2}-r_{2}^{2}}=\frac{2 C_{1}^{2}}{C_{1}^{2}-1}+\frac{C_{2}^{2}+1}{C_{2}^{2}-1}$

$$
\begin{aligned}
& k=\frac{r_{4}^{2}+r_{1}^{2}}{r_{4}^{2}-r_{1}^{2}}-\frac{r_{1}^{2}}{r_{2}^{2}}\left[\frac{r_{4}^{2}+r_{2}^{2}}{r_{4}^{2}-r_{1}^{2}}\right]=\frac{C_{1}^{2} C_{2}^{2} C_{3}^{2}+1}{C_{1}^{2} C_{2}^{2} C_{3}^{2}-1}-\frac{C_{2}^{2} C_{3}^{2}+1}{C_{1}^{2} C_{2}^{2} C_{3}^{2}-1} \\
& l=\frac{2 r_{3}^{2}}{r_{3}^{2}-r_{2}^{2}}=\frac{2 C_{2}^{2}}{C_{2}^{2}-1}
\end{aligned}
$$

Hence $P_{s 12}=P_{i}[k / j]+P_{s 23}[l / j]$

By equating equations (22) and (23) i. e. $\sigma_{\theta 2}=\sigma_{\theta 3}$ and rearranging,

$$
P_{s 12} \frac{r_{3}^{2}+r_{2}^{2}}{r_{3}^{2}-r_{2}^{2}}=P_{i}\left[\frac{r_{1}^{2}\left(r_{4}^{2}+r_{3}^{2}\right)}{r_{3}^{2}\left(r_{4}^{2}-r_{1}^{2}\right)}-\frac{r_{1}^{2}\left(r_{4}^{2}+r_{2}^{2}\right)}{r_{2}^{2}\left(r_{4}^{2}-r_{1}^{2}\right)}\right]+P_{s 23}\left[\frac{r_{4}^{2}+r_{3}^{2}}{r_{4}^{2}-r_{3}^{2}}+\frac{2 r_{3}^{2}}{r_{3}^{2}-r_{2}^{2}}\right]
$$

Let $\quad m=\frac{r_{3}^{2}+r_{2}^{2}}{r_{3}^{2}-r_{2}^{2}}=\frac{C_{2}^{2}+1}{C_{2}^{2}-1}$ 


$$
\begin{aligned}
& n=\frac{r_{1}^{2}\left(r_{4}^{2}+r_{3}^{2}\right)}{r_{3}^{2}\left(r_{4}^{2}-r_{1}^{2}\right)}-\frac{r_{1}^{2}\left(r_{4}^{2}+r_{2}^{2}\right)}{r_{2}^{2}\left(r_{4}^{2}-r_{1}^{2}\right)}=\frac{C_{3}^{2}+1}{C_{1}^{2} C_{2}^{2} C_{3}^{2}-1}-\frac{C_{2}^{2} C_{3}^{2}+1}{C_{1}^{2} C_{2}^{2} C_{3}^{2}-1} \\
& o=\frac{r_{4}^{2}+r_{3}^{2}}{r_{4}^{2}-r_{3}^{2}}+\frac{2 r_{3}^{2}}{r_{3}^{2}-r_{2}^{2}}=\frac{C_{3}^{2}+1}{C_{3}^{2}-1}+\frac{2 C_{2}^{2}}{C_{2}^{2}-1}
\end{aligned}
$$

Hence $P_{s 12}=P_{i}[n / m]+P_{s 23}[o / m]$

Solving equations (29) and (33) to get $P_{s 12}$ and $P_{s 23}$ in terms of $P_{i}$ as follows,

$$
\begin{aligned}
& P_{s 12}=P_{i}\left[\frac{(n / o)-(k / l)}{(m / o)-(j / l)}\right] \\
& P_{s 23}=P_{i}\left[\frac{(n / m)-(k / j)}{(l / j)-(o / m)}\right]
\end{aligned}
$$

Putting the values of $C_{1}, C_{2}$ and $C_{3}$, the equations (12) and (19) can be written as

$$
\begin{aligned}
& \delta_{12}=\frac{P_{s 12} r_{2}}{E}\left[\left(\frac{C_{2}^{2}+1}{C_{2}^{2}-1}\right)+\left(\frac{C_{1}^{2}+1}{C_{1}^{2}-1}\right)\right]-\frac{2 P_{s 23} r_{2}}{E}\left[\frac{C_{2}^{2}}{C_{2}^{2}-1}\right] \\
& \delta_{23}=\frac{P_{s 23} r_{3}}{E}\left[\left(\frac{C_{3}^{2}+1}{C_{3}^{2}-1}\right)+\left(\frac{C_{2}^{2}+1}{C_{2}^{2}-1}\right)\right]-\frac{2 P_{s 12} r_{3}}{E}\left[\frac{1}{C_{2}^{2}-1}\right]
\end{aligned}
$$

\subsection{Analytical Calculations for Optimum Design}

Material for all the three cylinders is assumed to be the same i. e. steel. For the given volume of fluid to be stored, the internal diameter of cylinder $1\left(d_{1}\right)$ is known. Here it is assumed as $100 \mathrm{~mm}$. Yield strength of the steel material is $\sigma_{y}=250 \mathrm{MPa}$. In case of pressure vessels it is observed that failure occurs across the thickness of cylinder where the hoop stress is acting. Although the von Mises stress is more than the hoop stress, it is acting on larger area than hoop stress. So chances of failure due to hoop stress is more in pressure vessel. Hence maximum hoop stress criteria is used for material suffering. Maximum principal stresses in all the cylinders (here it is maximum hoop stress) should not exceed the yield stress of the material to avoid the failure of the compound cylinder. Optimum material volume (length is assumed as unity) can be calculated using the following steps.

\section{Steps in Optimum Design}

1. Assume internal diameter of cylinder $1\left(d_{1}\right)$ say $100 \mathrm{~mm}$.

2. Select the ratios $C_{1}=\frac{r_{2}}{r_{1}}=\frac{d_{2}}{d_{1}}, C_{2}=\frac{r_{3}}{r_{2}}=\frac{d_{3}}{d_{2}}, C_{3}=\frac{r_{4}}{r_{3}}=\frac{d_{4}}{d_{3}}$

3. For the given internal pressure $P_{i}$, one can find contact (shrinkage) pressures $P_{s 12}$ and $P_{s 23}$ in terms of ratios $C_{1}, C_{2}$ and $C_{3}$ using equations (34) and (35).

4. Find the volume of the compound cylinder using $F X=\pi \cdot\left(d_{4}^{2}-d_{1}^{2}\right) / 4$

5. Minimize the volume subjected to the constraints,
i) $\sigma_{\theta 1}<=\sigma_{y}$
ii) $\sigma_{\theta 2}<=\sigma_{y}$
iii) $\sigma_{\theta 3}<=\sigma_{y}$
iv) $\delta_{12}>0$ v) $\delta_{23}>0$

6. Optimized parameters $C_{1}, C_{2}, C_{3}$ and $\delta_{12}, \delta_{23}$ are used for the design.

By selecting the various values if $C_{1}, C_{2}, C_{3}$ and using iterative numerical method (with the help of computer programming), contact (shrinkage) pressures $P_{s 12}$ and $P_{s 23}$ for given internal pressure $P_{i}$ are calculated using equations (34) and (35) resp. These contact pressures are then used to find interferences $\delta_{12}, \delta_{23}$ with the help of equations (36) and (37) resp. Volume is minimized subjected to the above said constraints.

A lot of combinations for $C_{1}, C_{2}, C_{3}$ starting from 1.1 to 1.5 with increment of $0.10,0.05,0.02$ have been tried. Actually the condition that maximum hoop stresses in all three cylinders being equal is met by number of combinations of $C_{1}, C_{2}, C_{3}$. Due to this, the output of the computer program is very long. Out of these some selected combinations have been included in this paper where volume is relatively less as compared to rest of the combinations. But for only one set, the volume is minimum. To show that, six sets of combination of $C_{1}, C_{2}, C_{3}$ have been listed. Using the 6 selected combinations of $C_{1}, C_{2}, C_{3}$ diameters $d_{2}, d_{3}, d_{4}$ and $\delta_{12}, \delta_{23}$ are calculated through computer program and results are listed in the table1. 
Table 1: Analytical Results of numerical method using computer program (for $d_{1}=100 \mathrm{~mm}$ and $\sigma_{y}=250 \mathrm{MPa}$ )

\begin{tabular}{|c|r|r|r|r|r|r|}
\hline $\begin{array}{c}\text { Combination of } C_{1}, C_{2}, C_{3} \rightarrow \\
\text { Parameters } \downarrow\end{array}$ & \multicolumn{1}{|c|}{ Set 1 } & \multicolumn{1}{c|}{ Set 2 } & \multicolumn{1}{c|}{ Set 3 } & \multicolumn{1}{c|}{ Set 4 } & Set 5 & Set 6 \\
\hline$C_{1}$ & 1.200 & 1.200 & 1.250 & 1.450 & 1.160 & 1.200 \\
\hline$C_{2}$ & 1.300 & 1.450 & 1.250 & 1.300 & 1.360 & 1.300 \\
\hline$C_{3}$ & 1.450 & 1.300 & 1.450 & 1.200 & 1.430 & 1.440 \\
\hline$d_{2}(\mathrm{~mm})$ & 120.000 & 120.000 & 125.000 & 145.000 & 116.000 & 120.000 \\
\hline$d_{3}(\mathrm{~mm})$ & 156.000 & 174.000 & 156.250 & 188.500 & 157.760 & 156.000 \\
\hline$d_{4}(\mathrm{~mm})$ & 226.200 & 226.200 & 226.562 & 226.200 & 225.597 & 224.640 \\
\hline$F x($ Volume $)\left(\mathrm{mm}^{3}\right)$ & 32331.400 & 32331.330 & 32460.230 & 32331.330 & 32117.320 & $\mathbf{3 1 7 7 8 . 9 8 0}$ \\
\hline$\sigma_{\theta 1}(\mathrm{MPa})$ & 247.496 & 247.496 & 246.135 & 247.496 & 249.868 & 249.719 \\
\hline$\sigma_{\theta 2}(\mathrm{MPa})$ & 247.496 & 247.496 & 246.135 & 247.496 & 249.868 & 249.719 \\
\hline$\sigma_{\theta 3}(\mathrm{MPa})$ & 247.496 & 247.496 & 246.135 & 247.496 & 249.868 & 249.719 \\
\hline$\delta_{12}(\mathrm{~mm})$ & 0.022 & 0.022 & 0.027 & 0.045 & 0.018 & 0.022 \\
\hline$\delta_{23}(\mathrm{~mm})$ & 0.032 & 0.046 & 0.027 & 0.034 & 0.038 & 0.032 \\
\hline$P_{s 12}(\mathrm{MPa})$ & 18.939 & 18.939 & 22.471 & 32.501 & 15.718 & 18.922 \\
\hline$P_{s 23}(\mathrm{MPa})$ & 20.996 & 21.581 & 20.778 & 17.910 & 21.867 & 20.894 \\
\hline
\end{tabular}

From the table it is observed that minimum volume is $31778.980 \mathrm{~mm}^{3}$ corresponding to values in set number $\mathbf{6}$ where $C_{1}=1.200, C_{2}=1.300, C_{3}=1.440$.

\section{Validation Procedure by FEM}

Now-a-days in the industry FEM is widely used due to its reliability. In the present analysis, certain assumptions are made and to validate these assumptions, FEM solutions is used.

By taking the corresponding values of $C_{1}, C_{2}, C_{3}$ from the set number 6 of the table 1 and taking $d_{1}=100$ mm remaining diameters $d_{2}, d_{3}, d_{4}$ are calculated. Using the values of $\delta_{12}, \delta_{23}$ shrink fit is applied between cylinders $1 \& 2$ and between cylinders $2 \& 3$ respectively in ANSYS Workbench. Contact between cylinders $1 \& 2$ as well as between cylinders $2 \& 3$ is applied using contact tool in ANSYS Workbench. The values of $\delta_{12}, \delta_{23}$ are radius based. These values are doubled to take diametric effect in the Finite Element Model.

Table 2: Data for modeling in ANSYS (for set number 6) to validate analytical results

\begin{tabular}{|c|c|c|c|c|c|c|c|c|c|}
\hline$C_{1}$ & $C_{2}$ & $C_{3}$ & $d_{2}$ & $d_{2 i}$ & $d_{3}$ & $d_{3 i}$ & $d_{4}$ & $\delta_{12}$ & $\delta_{23}$ \\
\hline 1.200 & 1.300 & 1.440 & 120.000 & 119.956 & 156.000 & 155.936 & 224.640 & 0.022 & 0.032 \\
\hline
\end{tabular}

where $\quad d_{1}, d_{2}=$ inner \& outer diameters of cylinder 1 respectively.

$d_{2 i}, d_{3}=$ inner $\&$ outer diameters of cylinder 2 respectively for shrink fit.

$d_{3 i}, d_{4}=$ inner \& outer diameters of cylinder 3 respectively for shrink fit.

FEM model of three layered compound cylinder is prepared in ANSYS Workbench using values of the diameters from table 2. Results of FEM by ANSYS Workbench are listed in the figures 13, 14, 15, 16, 17. 


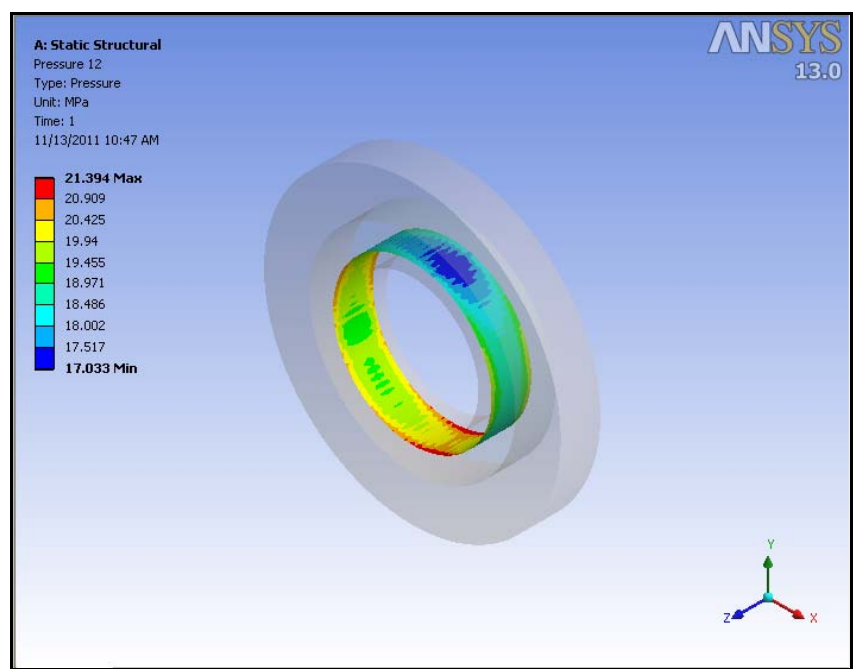

Figure 13. $P_{s 12}$ (without $\left.P_{i}\right)=19.21 \mathrm{MPa}($ Avg)

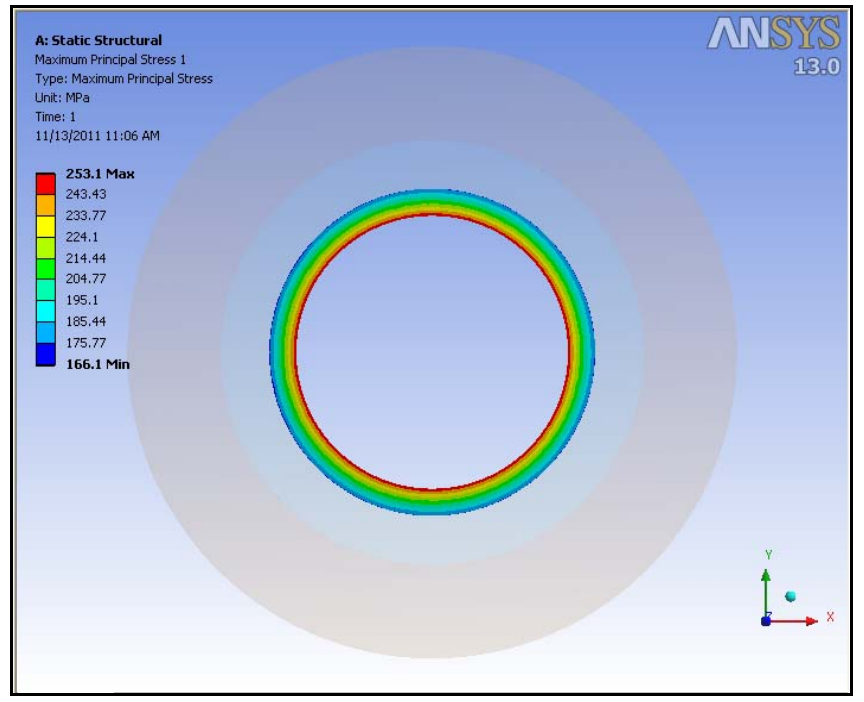

Figure 15. Maximum Principal Stress in cylinder 1

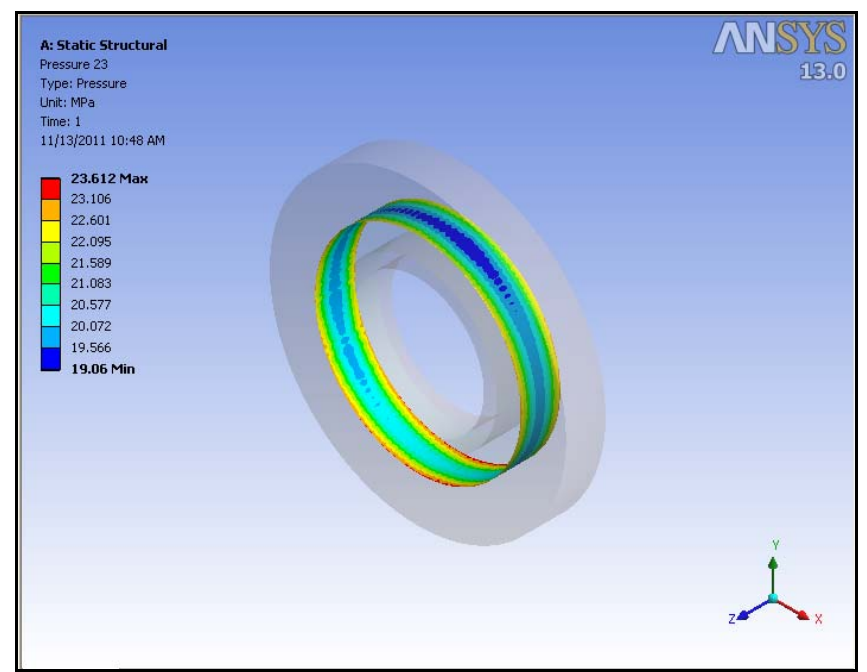

Figure 14. $\quad P_{s 23}$ ( without $\left.P_{i}\right)=21.33 \mathrm{MPa}($ Avg)

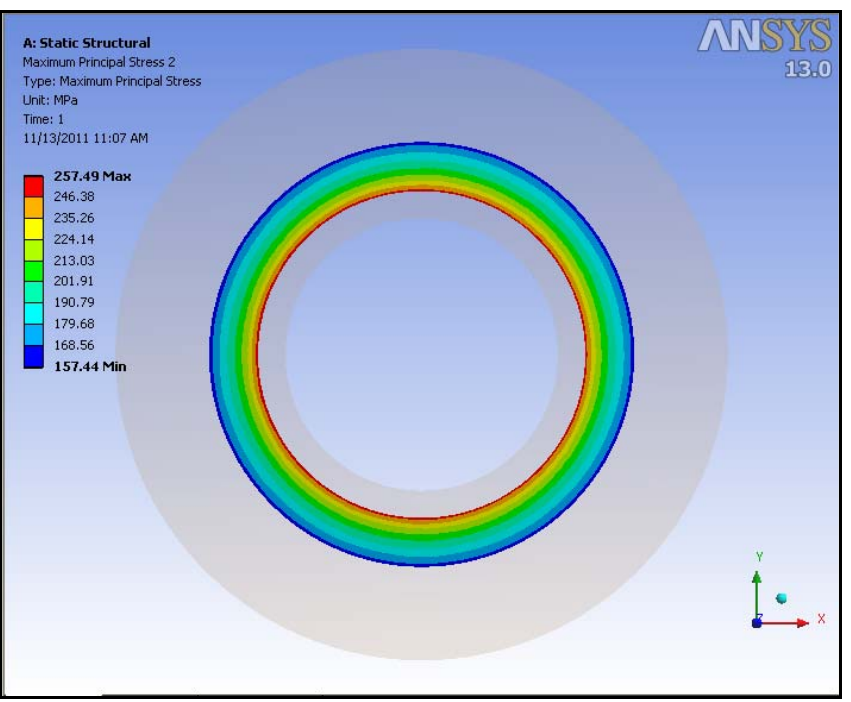

Figure 16. Maximum Principal Stress in cylinder 2

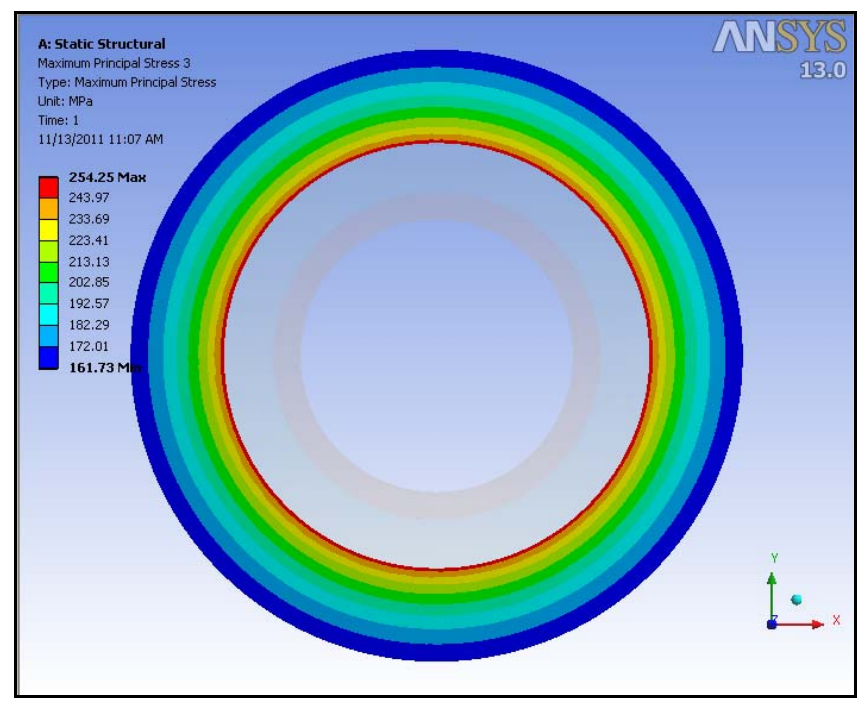

Figure 17. Maximum Principal Stress in cylinder 3 


\section{Results}

Analytical results and FEM (ANSYS) results are summarized in Table 3.

Table 3: Comparison of Analytical and ANSYS results for 6 combination sets of $C_{1}, C_{2}, C_{3}$

\begin{tabular}{|c|c|c|c|c|c|c|}
\hline $\begin{array}{l}\text { Set } \\
\text { No }\end{array}$ & Results & $\begin{array}{c}P_{s 12} \\
\text { (MPa) }\end{array}$ & $\begin{array}{c}P_{s 23} \\
\text { (MPa) }\end{array}$ & $\begin{array}{c}\sigma_{\theta 1} \\
\text { (MPa) }\end{array}$ & $\begin{array}{c}\sigma_{\theta 2} \\
\text { (MPa) }\end{array}$ & $\begin{array}{c}\sigma_{\theta 3} \\
(\mathbf{M P a})\end{array}$ \\
\hline \multirow{3}{*}{ Set 1} & Analytical & 18.939 & 20.996 & 247.496 & 247.496 & 247.496 \\
\hline & ANSYS & 19.620 (Avg) & 21.705 (Avg) & 250.270 & 251.850 & 251.730 \\
\hline & Difference & $3.59 \%$ & $3.37 \%$ & $1.12 \%$ & $1.77 \%$ & $1.71 \%$ \\
\hline \multirow{3}{*}{ Set 2} & Analytical & 18.939 & 21.581 & 247.496 & 247.496 & 247.496 \\
\hline & ANSYS & 19.530 (Avg) & 22.085 (Avg) & 250.990 & 251.190 & 253.270 \\
\hline & Difference & $3.12 \%$ & $2.33 \%$ & $1.41 \%$ & $1.49 \%$ & $2.33 \%$ \\
\hline \multirow{3}{*}{ Set 3} & Analytical & 22.471 & 20.778 & 246.135 & 246.135 & 246.135 \\
\hline & ANSYS & 22.630 (Avg) & 21.510 (Avg) & 249.230 & 250.200 & 250.520 \\
\hline & Difference & $0.70 \%$ & $3.52 \%$ & $1.25 \%$ & $1.65 \%$ & $1.78 \%$ \\
\hline \multirow{3}{*}{ Set 4} & Analytical & 32.501 & 17.910 & 247.496 & 247.496 & 247.496 \\
\hline & ANSYS & 32.593 (Avg) & 18.073 (Avg) & 248.960 & 254.740 & 250.750 \\
\hline & Difference & $0.28 \%$ & $0.91 \%$ & $0.59 \%$ & $2.92 \%$ & $1.31 \%$ \\
\hline \multirow{3}{*}{ Set 5} & Analytical & 15.718 & 21.867 & 249.868 & 249.868 & 249.868 \\
\hline & ANSYS & 16.203 (Avg) & 22.165 (Avg) & 254.490 & 253.730 & 254.350 \\
\hline & Difference & $3.08 \%$ & $1.36 \%$ & $1.84 \%$ & $1.54 \%$ & $1.79 \%$ \\
\hline \multirow{3}{*}{ Set 6} & Analytical & 18.922 & 20.894 & 249.719 & 249.719 & 249.719 \\
\hline & ANSYS & 19.210 (Avg) & 21.330 (Avg) & 253.100 & 257.490 & 254.250 \\
\hline & Difference & $1.52 \%$ & $2.08 \%$ & $1.35 \%$ & $3.11 \%$ & $1.81 \%$ \\
\hline
\end{tabular}

From the table 3, it is observed that there is very small difference in analytical and FEM results, i. e. FEM gave virtually similar results as the analytical results (Refer to Figure 18).

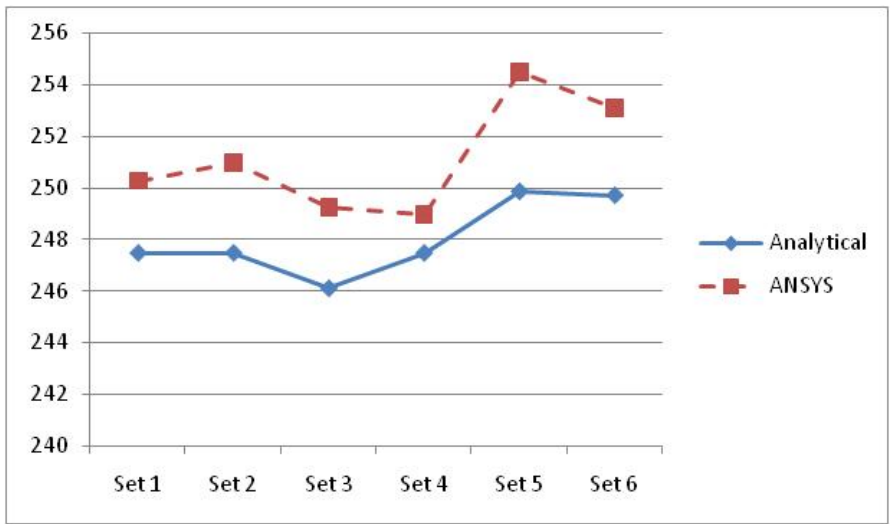

(a) $\sigma_{\theta 1}$ in $\mathrm{MPa}$

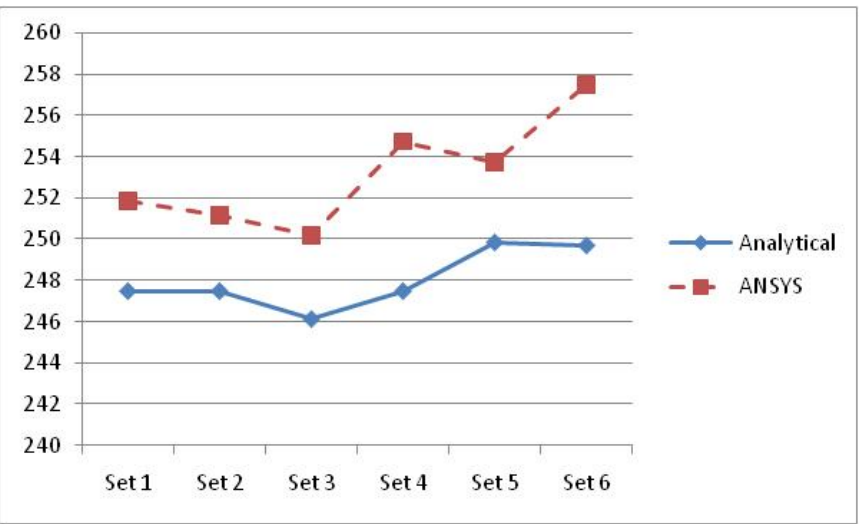

(b) $\sigma_{\theta 2}$ in $\mathrm{MPa}$ 


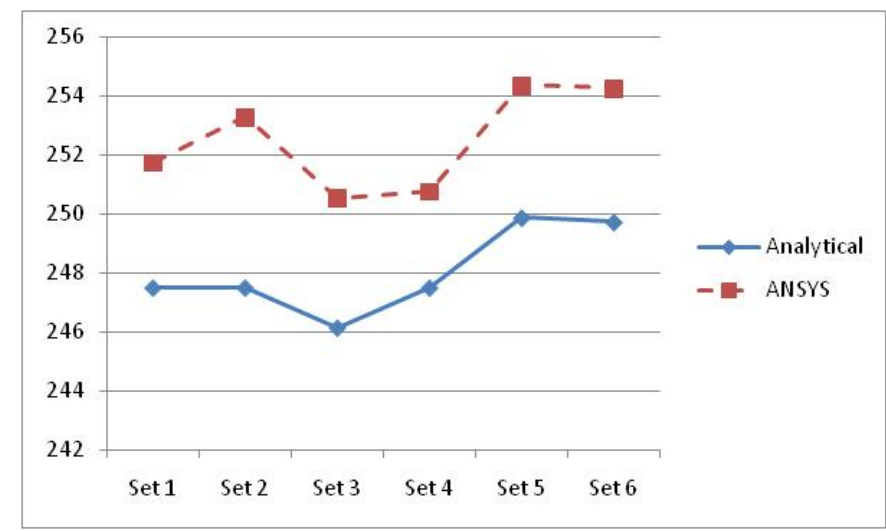

(c) $\sigma_{\theta 3}$ in $\mathrm{MPa}$

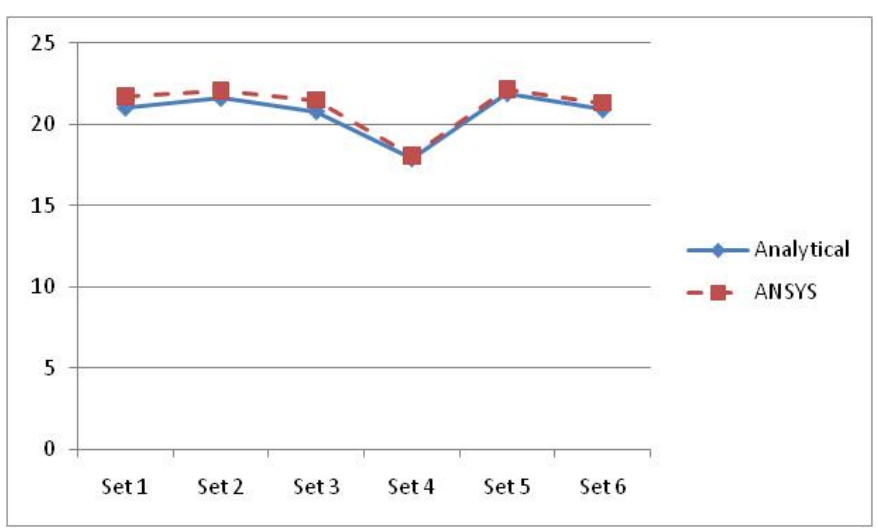

(e) $P_{s 23}$ in MPa (without internal pressure)

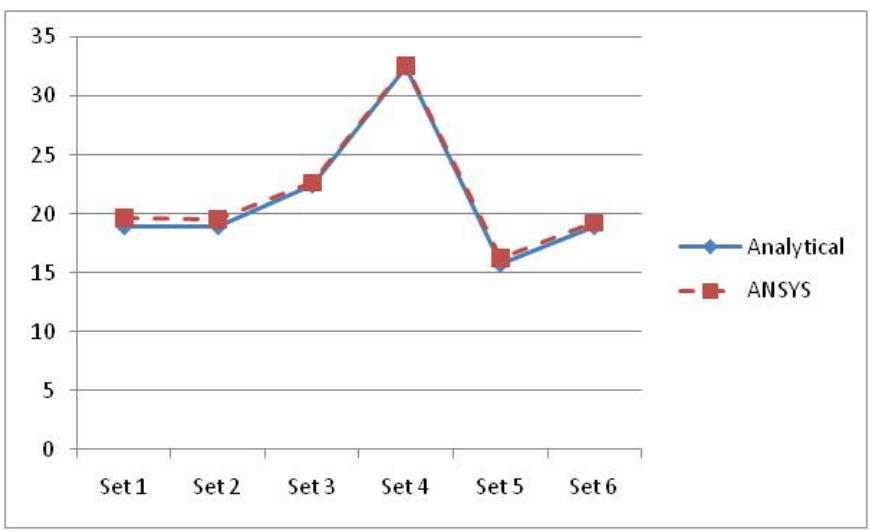

(d) $P_{s 12}$ in MPa (without internal pressure)

Figure 18: Difference in analytical and ANSYS Software results

\section{Conclusion}

The difference between analytical results and ANSYS results is below $4 \%$ with respect to analytical results. This difference is due to numerical techniques of Finite Element Method in ANSYS. Since analytical results are validated by FEM calculations, the design methodology proposed in this paper can be successfully applied into the real-world mechanical applications for minimizing the material volume of multi-layered compound cylinders to assure best utilization of material. Patil (2005) proposed the optimization of intermediate, outer diameter and shrinkage tolerance to get minimum volume of two layer compound cylinders as $37974.94 \mathrm{~mm}^{3}$. In comparison with this, proposed methodology for three layer compound cylinders gave volume as 31778.980 $\mathrm{mm}^{3}$ (for same internal diameter $=100 \mathrm{~mm}$ and same material of $\sigma_{y}=250 \mathrm{MPa}$ ) which is quite significant to save the material and serve the purpose.

\section{Acknowledgement}

The author is grateful to the Management, Executive Director, Principal, Head-Department of Mechanical Engineering of MIT College of Engineering, Pune, India for time to time encouragement and support in carrying out this research work.

\section{References}

Gibson M.C., 2008, Determination of residual stress distributions in autofrettaged thick-walled cylinders, Cranfield University, Defense College of Management and Technology United Kingdom, Ph. D. Thesis, April 2008.

Hamid J., Behrooz F., Morvarid K., 2006, Optimum autofrettage and shrink-fit combination in multi-layer cylinders, Journal of Pressure Vessel Technology, Transactions of the ASME, pp. 196-200, Vol. 128.

Hojjati M.H., Hassani A., 2007, Theoretical and finite-element modeling of autofrettage process in strain-hardening thick-walled cylinders, International Journal of Pressure Vessels and Piping, Vol. 84, pp. 310-319.

Lee E.-Y., Lee Y.-S., Yang Q.-M., Kim J.-H., Cha K.-U. and Hong S.-K., 2009, Autofrettage process analysis of a compound cylinder based on the elastic-perfectly plastic and strain hardening stress-strain curve, Journal of Mechanical Science and Technology, Vol. 23, pp. 3153 3160. 
Majzoobi G.H. and Ghomi A., 2006, Optimization of compound pressure cylinders, Journal of Achievements in Materials and Manufacturing Engineering, Vol. 15, No. 1-2 March-April.

Park J.-H., Lee Y.-S., Kim J.-H., Cha K.-U., Hong S.-K., 2008, Machining effect of the autofrettaged compound cylinder under varying overstrain levels, Journal of Materials Processing Technology, pp. 491-496.

Patil S. A., 2011, Finite Element Analysis of optimized compound cylinder, Journal of Mechanical Engineering Research, Vol. 3, No. 1, Issue March.

Patil S. A., 2005, Optimum design of compound cylinder used for storing pressurized fluid, ASME International Mechanical Engineering Congress and Exposition (Proceeding of IMECE05), Nov 5-11,2005,Orlando, Florida USA.

Torbacki W., 2007, Numerical strength and fatigue analysis in application to hydraulic cylinders, Journal of Achievements in Materials and Manufacturing Engineering, Vol. 25, No. 2, pp. 65-68.

Yang Q.-M., Lee Y.-S., Lee E.-Y., Kim J.-H., Cha K.-U. and Hong S.-K., 2009, A residual stress analysis program using a Matlab GUI on an autofrettaged compound cylinder, Journal of Mechanical Science and Technology, Vol. 23, No. 11, pp. $2913-2920$.

\section{Biographical notes}

A. A. Miraje is a Assistant Professor in the Department of Mechanical Engineering at, M I T College of Engineering, Pune, India. He has 27 years of teaching experience and 1 year of industrial experience. He has to his credit 10 papers in International and National Conferences. His research interests include design optimization, finite element analysis, computer aided design and manufacturing, analysis and synthesis of mechanism, vibration. He is a Life Member of ISTE (India).

Dr. S. A. Patil is a Professor in the Department of Mechanical Engineering at Sinhgad Institute of Technology and Science, Pune, India. He has 10 years of industrial experience and 17 years of teaching experience. He has to his credit 4 papers in International Conferences and 4 papers in International Journals. His research interests include computer aided design and manufacturing, Robotics, computational fluid dynamics, design optimization.

Received September 2011

Accepted December 2011

Final acceptance in revised form February 2012 